\title{
Improvement of Repair Impact Efficiency During Technical Operation of Diesel Engines
}

\author{
Rinat Ralifovich Gainiev ${ }^{1}$, Aleksey Yurevich Barykin², Rayaz Khalimovich Takhaviev², \\ Damir Imamutdinovich Nuretdinov ${ }^{4}$ \\ ${ }^{1}$ st year master's student, Automotive Department, Kazan Federal University, Russia. \\ ORCID 0000-0002-7536-3004 \\ ${ }^{2}$ PhD in engineering, Associate Professor, Automotive Department, Kazan Federal University, Russia. \\ ID scopus 57212536899, ORCID 0000-0001-8552-1451 \\ ${ }^{3}$ Senior Lecturer, Automotive Department, Kazan Federal University, \\ ID scopus 56459011300, ORCID 0000-0002-1175-2334 \\ ${ }^{4} \mathrm{PhD}$ in engineering, Associate Professor, Automotive Department, Kazan Federal University, \\ ID scopus 57192100502, ORCID 0000-0002-2455-0563,
}

\begin{abstract}
The article is devoted to the issues of truck power unit operability and reliability provision during the service life. They considered the need for repair work at a certain moment corresponding to the maximum permissible values of part wear. The analysis of the technical condition of the cylinder-piston group parts of KAMAZ diesel engines was carried out and the main causes of malfunctions during operation were established. The dynamics of wear processes was studied taking into account the working processes of the engine, the material and the state of the part surface, the physicochemical properties of engine oil and diesel fuel. The authors have proposed an original approach to the issue of the repair action timeliness, based on the information about the indicators of the engine technical condition undergoing preventive measures and overhaul. The paper provides expressions to determine the criterion of the residual life, by which it is proposed to assess the rationality of the repair impact. Based on the analysis of the known methods of diesel engine part restoration, the expediency of surfacing and plasticization of cylinder liner surfaces is substantiated. The advantages and disadvantages of the selected repair method are considered. They provided the assessment of engine part restoration economic efficiency during repair.
\end{abstract}

Keywords: Automobile, Diesel Engine, Cylinder-Piston Group, Restoration Of Parts, Surfacing, Preventive Repair.

\section{INTRODUCTION}

The assessment of an operated diesel engine technical condition is usually based on a number of the most important indicators. These, as a rule, include the maximum power and maximum torque, fuel consumption and engine oil waste, the composition of exhaust gases and noise. The reasons for the change in these indicators are, first of all, mechanical damage and wear of the main parts, which significantly depend on the operating conditions of the cylinder-piston group, primarily on the action of alternating loads and high temperatures. Addi- tional factors in this case are the abrasive properties of materials and foreign contamination, plastic deformation of parts, corrosion phenomena of the engine working process. In this case, the side types of damage to the parts can be called the formation of carbon deposits and warpage of parts that occur under severe operating conditions.

The analysis of scientific literature makes it possible to establish the relationship between various physical and chemical phenomena accompanying the working process of a diesel engine [7-11]. For example, the use of welded joints of parts made of chromium steels can cause intergranular corrosion. Simultaneous exposure to an unfavorable environment and high temperatures can lead to corrosion cracking of parts. The friction of parts in a contaminated lubricant environment is the cause of hydroabrasive wear. Carbon deposits on the surface of parts leads to the formation of cracks in some cases, due to excessive local heating.

In all cases of wear part loading, it is fundamentally important to assess the intensity of wear during different periods of operation [12]. It is customary to distinguish three consecutive phases of wear: an initial short running-in phase with a high level of wear, a long main phase of smooth natural wear, and a final phase with a high wear rate reaching the maximum permissible values. The moment of any type of repair should correspond to the completion of the main phase and not go into the final phase, as this is fraught with significant losses.

\section{METHODS}

Reliable information about the dependence of part wear on their service life, usually measured in load cycles, makes it possible to exclude sudden breakdowns of parts and ensure timely repair or replacement with a high probability.

The frequency of repairs and replacement of parts for diesel engines is an important indicator that determines the strategy of vehicle technical operation in general. To ensure the efficiency of work, various types of repairs are used in a certain sequence. The thing is about preventive and major repairs, the 
number of which may vary depending on the chosen strategy.

The best known are three variants of the maintenance strategy: with three major engine overhauls before decommissioning; with the first preventive, major and second preventive repairs; with the first and second preventive, major and third preventive repairs. With regard to diesel engines KAMAZ-740 and the most probable third category of operating conditions, the second strategy is usually used. The approximate terms of the repairs are 120 thousand $\mathrm{km}$ of the vehicle mileage before the first preventive repair, 200 thousand $\mathrm{km}$ - before the overhaul and 280 thousand $\mathrm{km}$ - before the second preventive repair.

A number of engine parts are replaced both during preventive and overhaul repairs, since their wear is a significant factor in power unit performance and failure reduction. Such parts include the crankshaft, cylinder liners, pistons and piston pins, connecting rods, head gaskets, main and connecting rod bearings, and piston rings. At the same time, the replacement of some parts makes it possible to exclude the repair of others, for example, the replacement of the piston rings allows to avoid the replacement and repair of cylinder liners.

The technical condition of a diesel engine before preventive and overhaul repairs is usually assessed by a number of indicators. For an objective assessment, they take into account both the dimensions and deviations of the part shape that are changed due to mechanical or corrosion-mechanical wear (for example, wear and ovality of the connecting rod journals) and operating parameters (pressure and engine oil consumption), which are also influenced by the abovementioned factors.

In [13] it is indicated that the violations of engine part manufacturing technology, in particular, cylinder liners, can lead to the violation of their geometry after the engine assembly and affect its resource.

In article [14], the technology of cylinder liner is considered and the need to take into account the material properties and the cylinder unit manufacturing technology is noted.

It is also necessary to take into account the influence of the physicochemical properties of engine oil, also under adverse environmental influences. For example, starting and operating the engine in the cold season can significantly affect the course of working processes due to violation or deviation from the standard values of dynamic viscosity and other oil parameters.

It is known from operational practice that the reasons for the failure of KAMAZ diesel engines may differ in terms of repair impact periods. So, during the period before overhaul without preventive repair, the most frequent reasons for failure are cranking of the liners and wear of the cylinder-piston group parts $(69 \%$ by the amount of failures), during the period after preventive repair - the wear of the cylinder-piston group parts and crankshaft bearings $(72.1 \%)$, during the period after major repairs - turning of liners, cracks and the seizure of cylinder liners $(57.5 \%)$.

A rational approach to the planning of repair actions and the choice of technologies for the restoration of parts will ensure the mileage of vehicles with a sufficiently long turnaround time, excluding preventive repairs.
The analysis of scientific literature and information on the technical operation of KAMAZ vehicles allows us to draw the following conclusions about the state of affairs and further ways to solve the problem of repair action efficiency improvement:

1. The effect of mechanical, corrosive and corrosionmechanical wear is fundamentally important for the performance of piston rings and liners.

2. The main factor determining the need for preventive maintenance is the wear of the upper compression ring.

3. The exclusion of preventive maintenance while maintaining a sufficient overhaul period (before overhaul) is possible when they implement the measures that increase the durability of the pair "upper compression ring - cylinder liner" by 1.5-1.6 times.

To increase the durability of the upper compression ring and sleeve, their corrosion resistance should be increased.

\section{RESULTS AND DISCUSSION}

The analysis of the working processes and operating conditions of the cylinder-piston group shows that the timeliness of the repair action is determined not by one or several parameters, but by a set of design and operational parameters that determine the engine state and the residual life of its components. An early impact is economically disadvantageous, while later exposure may not be implemented due to premature failure.

A reliable assessment of the expected wear of parts and, for known operating conditions, the residual life of the cylinderpiston group, can be made based on the available information about the wear of parts during the overhaul periods of operation. As was noted above, the influence of the lubricating medium must be taken into account.

To assess the feasibility of carrying out repair actions, the authors proposed the criterion for the residual life of the cylinder-piston group $\Lambda_{R}$, expressed as follows:

$\Lambda_{R}=\Sigma\left(\chi_{i} Q_{i}\right) / n$,

$Q_{i}=\left(S_{p i}-S_{t i}\right) /\left(S_{k i}-S_{t i}\right)$,

where $\mathrm{S}_{\mathrm{ti}}$ is the current value of the $\mathrm{i}$-th technical condition indicator; $S_{\mathrm{pi}}$ - the average value of the $\mathrm{i}$-th technical condition indicator before preventive maintenance; $\mathrm{S}_{\mathrm{ki}}$ - the average value of the i-th technical condition indicator before overhaul; $\mathrm{Q}_{\mathrm{i}}$ - a particular criterion of the residual life of the cylinderpiston group by the $\mathrm{i}$-th technical condition indicator; $\chi_{i}-$ the weighting coefficient of the corresponding particular criterion of the residual resource, $\mathrm{n}$ - the number of technical condition indicators taken into account during the calculation.

The technical condition indicators recommended by the authors are listed below. These include the wear and ovality of the connecting rod journals, the wear of the main journals, the wear of the connecting rod and main bearings, the clearances in the connecting rod and main bearings, the pressure in the lubrication system at the minimum and rated speed, the wear 
and ovality of cylinder liners in the upper belt, the radial wear of the upper compression and oil scraper rings, the clearances in the "piston groove - upper compression ring" and "piston groove - oil scraper ring" joints, and oil consumption for waste.

The study of the working processes of a diesel engine made it possible to verify the presence of various types of wear, in particular, molecular-mechanical, corrosion-mechanical and abrasive. The predominance of one type of wear is possible under certain operating conditions and can be detected by the shape of the cylinder wear gradient along the generatrix. Accordingly, the loading conditions of the piston rings are also different, also for different cylinders of the same engine. The study carried out by domestic scientists has proven a stable correlation between the average wear of parts of the cylinderpiston group in different climatic conditions. This allows us to speak about the rationality of taking into account the properties of a set of details proposed in this article.

There are various methods of worn-out surface restoration for cylinder-piston group parts used in industry [14-16]. In particular, chrome plating is used for the parts made of nitrosulphided cast irons, nitriding is used for the parts made of cast irons alloyed with aluminum. However, such methods are very expensive and not widely used. The galvanomechanical method, due to the mechanical activation of the treated surface, makes it possible to achieve a high process speed, but it also leads to significant costs. Powder surfacing with chromium-nickel alloys and plating with wear-resistant austenitic alloys is more efficient. Induction surfacing provides good properties of the restored metal layer, and allows automation of repair work with a relatively simple technology. The following disadvantages should be considered: the thermal effect on the base material of parts and the need to use relatively low-melting materials for recovery.

During the operation of KAMAZ engines, the following features are found that distinguish the requirements for repair effects in comparison with other diesel engines:

1. Relatively low wear of cylinders and pistons $(0.15-0.20 \mathrm{~mm}$ before maintenance or overhaul).

2. Lack of oversized pistons and forced replacement of cylinder liners when worn.

In this situation, it is rational to restore the sleeves by lining them with steel strip plates with prior and subsequent processing [16]. This method is used by repair companies. Usually they use cold-rolled strip made of high-hardness carbon steel (U8A and U10A grades), and of manganese steel 65G. The thickness of the plates for KAMAZ engine liners should be in the range of $0.5-0.7 \mathrm{~mm}$. The main advantage of this recovery method is the possibility of its use at small enterprises with limited production volumes. Besides, one should point out the ease of plated sleeve replacement, and, thus, high maintainability. The disadvantages of plating include some deterioration in the thermal state of the cylinder due to the presence of a heat transfer gradient over the liner area, as well as the complication of the repair process due to the need to individual adjustment of the plates for the liners with different wear.

\section{CONCLUSIONS}

Timely repair work allows to increase the reliability of the engine during operation, to ensure a sufficient overhaul mileage and a high service life in general. The combination of rational timing of preventive or overhaul repairs with highly efficient technology for the cylinder-piston group part restoration is the basis for implementing the chosen strategy of technical operation, which is the most economical and takes into account the working conditions.

The proposed method for the residual life evaluation of the cylinder-piston group allows to plan the frequency of repair actions with a high degree of reliability and with minimal economic losses. The residual life criterion, based on a set of wear indicators and parameters of the engine technical condition, makes it possible to assess objectively the feasibility of repairs.

The authors have established the economic feasibility of equipment introduction for plating and induction surfacing of cylinder liners during the overhaul of KAMAZ-740 engines. They performed an assessment of capital investment efficiency carried out with the introduction of the appropriate equipment, which showed a fairly short payback period for fixed assets ( 0.8 years). The use of the proposed technologies is highly relevant in the conditions that dictate the need to increase the level of after-sales service for cars.

\section{SUMMARY}

The materials of this article are based on the analysis of scientific information, and on observation data of KAMAZ diesel engine operation under various conditions. The assessment of the residual life of the cylinder-piston group was carried out on the basis of reliable information about the dynamics of technical indicators. The effectiveness of the recommended methods for restoration the parts of the cylinder-piston group is confirmed by the data of repair enterprise production activity. The selected repair technologies comply with the requirements of standards and technical specifications. Technical and economic calculations underlying the conclusions and recommendations of the work are based on generally accepted methods for economic efficiency evaluation.

\section{ACKNOWLEDGEMENTS}

The work is performed according to the Russian Government Program of Competitive Growth of Kazan Federal University.

\section{REFERENCES}

[1] Kulakov A, Gattarov I, Frolov A. Provision of gas engine bus performance with air-fuel mixture. Journal of Environmental Management \& Tourism. 2015 Jul 1;6(1 (11)):91-100

[2] Porisini FC. Salt hydrates used for latent heat storage: corrosion of metals and reliability of thermal 
International Journal of Engineering Research and Technology. ISSN 0974-3154, Volume 13, Number 11 (2020), pp. 3601-3604

(C) International Research Publication House. https://dx.doi.org/10.37624/IJERT/13.11.2020.3601-3604

performance. Solar Energy. 1988 Jan 1;41(2):193-7.

[3] Tyulkin VA. The study of changes in the temperature regime of car engines. The problems of technology adaptation to harsh conditions: The reports of scientificpractical conf. Tyumen: TyumGNGU. 1999:241 - 243.

[4] Kulakov AT, Gafiyatullin AA, Barylnikova EP. Providing normal conditions of lubricating of diesel engine during its operation. InIOP Conference Series: Materials Science and Engineering 2014 Jan 1 (Vol. 69, No. 1, p. 012027).

[5] Yakunin NN, Kalimullin RF. Transitional lubricating process in plain bearings in machines. Life Science Journal. 2014;11(12s):427-3.

[6] Remanufacturing Overhauling. Rebuilding. What's difference? Fleet maintenance and Specifing. 1982: 28-33; part 2, June 1982, pp. 29-32.

[7] Akhmetov ND, Gimadeev MM, Krivosheev VA. The study of the mounting macrogeometry of the cylinder liner of KAMAZ diesel engines by modeling in Siemens
NX. Final scientific conference: (2015; Naberezhnye Chelny). In 3 parts. Part 1. Final scientific. conf. of lecturers, February 13, 2015 [Text]: collection of reports. Naberezhnye Chelny: CPI of the Naberezhnye Chelny Institute K(P)FU, 2015: 148-152.

[8] Ivanov IG, Lapshin AS. Sleeve making for worn out aluminum blocks of passenger car engines. Problems of vehicle quality and operation: Road transport operation and development [Text]: materials of the X-th International scientific and technical conf. - Penza: PGUAS. 2015: 158-164.

[9] Isakov AA. Prospective technologies for the production of the connecting rod-piston group parts. Architecture, construction, transport [Electronic resource]: Materials of the International scientific-pr. conf. - Omsk: SibADI, 2015: 835-838. Access mode: http://bek.sibadi.org/fulltext/ESD75.pdf

[10] Sobolev NI, Titunin BA. Plating of machine parts. - L.: Mechanical engineering. Leningr. Department. 1987: $224 \mathrm{p}$.

Rinat Ralifovich Gainiev was born on September 20, 1994. Since 2019, he graduated from the Naberezhnye Chelny Institute (branch) of the Kazan Federal University, received the Bachelor's degree in the field of 03/23/03 "Operation of transport and technological machines and complexes." At the moment he is studying according to the master's program in the field of $04 / 23 / 03$ "Operation of transport and technological machines and complexes" of the master's program "Technical operation of cars" at the Naberezhnye Chelny Institute (branch) of the Kazan Federal University. He works in LLC "ROS-AUTO 3" as a master-inspector.

Barykin Alexey Yurievich. He was born in 1964. In 1987 he graduated from the Kama Polytechnic Institute with the degree in Automobiles and Tractors, in 1991 he finished the postgraduate studies at the Moscow Automotive Institute with the degree in "Wheeled and Tracked Vehicles". He defended his Ph.D. thesis in February 1992. In 1999 he was awarded the academic title of Associate Professor. Today he works as an Associate Professor at the Department of Operation of Automobile Transport, Kazan Federal University.

Rayaz Khalimovich Takhaviev was born in 1973. In 1995 he graduated from the Kama Polytechnic Institute with the degree in "Automobiles and Automotive Industry". In 2002 he graduated from the Kazan State Agricultural Academy by correspondence course with the degree in "Agricultural Mechanization. Today he works as a senior lecturer at the Department of "Road Transport Operations", Kazan Federal University.

Damir Imamutdinovich Nuretdinov was born on January 14, 1978. In 2000 he graduated from the Kama Polytechnic Institute, he received the diploma in the field of "Automobiles and Automotive Industry". In 2004 he defended his Ph.D. thesis in the field of 05.22.10 - "Operation of road transport". Today he works as an Associate Professor at the Department of "Automobile Transport Operation", Kazan Federal University. 